\title{
Disseminating Research with Web CV Hyperlinks ${ }^{1}$
}

\section{Kayvan Kousha}

Statistical Cybermetrics Research Group, School of Technology, University of Wolverhampton, Wulfruna Street, Wolverhampton WV1 1LY, UK E-mail: k.kousha@wlv.ac.uk

\section{Mike Thelwall}

Statistical Cybermetrics Research Group, School of Technology, University of Wolverhampton, Wulfruna Street, Wolverhampton WV1 1LY, UK. E-mail: m.thelwall@wlv.ac.uk

\begin{abstract}
Some academic web CVs, including homepages and publication lists, link to open access (OA) papers, resources, abstracts in publishers' websites, or academic discussions, helping to disseminate research. To assess how common such practices are and whether they vary by discipline, gender and country, we conducted a large scale email survey of astronomy and astrophysics, public health, environmental engineering, and philosophy across 15 European countries and analysed hyperlinks from academic web CVs. About $60 \%$ of the 2,154 survey responses reported having a web CV or similar and there were differences between disciplines, genders and countries. A follow-up outlink analysis of 2,700 web CVs found that a third had at least one outlink to an OA target, typically a public eprint archive or an individual self-archived file. This proportion was considerably higher in astronomy $(\mathbf{4 8 \%})$ and philosophy $(37 \%)$ than in environmental engineering $(29 \%)$ and public health $(21 \%)$. There were also differences in linking to publishers' websites, resources and discussions. Perhaps most importantly, however, the amount of linking to OA publications seems to be much lower than allowed by publishers and journals, suggesting that many opportunities for disseminating full-text research online are being missed, especially in disciplines without established repositories. Moreover, few academics seem to be exploiting their CVs to link to discussions, resources or article abstracts, which seems to be another missed opportunity for research publicity.
\end{abstract}

\section{Introduction}

Although scholars are often publically funded, the public and other researchers may have to pay to access their results and may find it difficult to discover basic information about publications, related resources, and relevant discussions. This may undermine the value of research by reducing its audience (Harnad, 2006) and can lead to the accidental duplication of research (http://cordis.europa.eu/tvp/src/quicksc.htm, European Commission). Open Access (OA) has thus been recognised as a key issue in the major Horizon 2020 funding programme (European Commission, 2012ab). Publishing in OA journals (gold OA) and self-archiving (green OA) are two different strategies to give free access to research. About $17 \%$ of Scopus indexed articles in 2011 were gold OA (12\% full immediate OA and 5\% delayed OA and hybrid OA) and gold OA journals grew $1 \%$ per year over the previous decade (Laakso \& Björk, 2012). Moreover, most journals (about 90\%) and many publishers (about 62\%) seem to let authors deposit article preprints or postprints online through personal homepages or institutional repositories (see, Harnad et al., 2008; SHERPA/RoMEO, 2013). Nevertheless, only 20\%-24\% of articles are being self-archived by authors (Björk et al., 2010; Gargouri et al., 2012b) and a large-scale survey across the EU found that most authors were unlikely to voluntarily self-archive (Creaser et al., 2010), so there is a large gap between the amount of self-archiving that it permitted and the amount that occurs.

In response, the European Commission has initiated an OA pilot to mandate research funded by the EU to be freely available (European Commission, 2012c), this covers only a

\footnotetext{
${ }^{1}$ This is a preprint of an article to be published in the Journal of the American Society for Information Science and Technology $@$ copyright 2013 John Wiley \& Sons, Inc.
} 
fraction of EU research. It is possible that future, stronger OA mandates may increase OA deposit rates, however (see Sale, 2006; Gargouri et al., 2012a).

This article focuses on one method of disseminating or publicising research: hyperlinks from web CVs. We took a large sample of European academics from four disciplines and assessed the extent of OA-linking CVs and the nature of the use of online CVs to publicise research. This does not reveal the full extent of OA use by scholars because articles may be published in OA journals or deposited in institutional or subject archives without CV hyperlinks, especially in astronomy and astrophysics. For example, an author may believe that peers will naturally search Google Scholar or a relevant subject repository and so web CV hyperlinks are superfluous. Nevertheless, links from CVs may at least give an additional access point, for example for those browsing the CVs of known experts. Perhaps because of this, multiple access points to OA research may increase citation impact (Xia, Myers \& Wilhoite, 2011). This article also investigates other ways of using web CVs to publicise research. Scholarly web CVs can direct readers to abstracts of articles and books in publishers' websites or research discussions and presentations in blogs, online videos and other social media tools (Shema, Bar-Ilan \& Thelwall, 2012; Sugimoto \& Thelwall, 2013). However, the extent to which individual academics use web CVs to help disseminate their research is unknown and this is a serious omission, given the apparently widespread use of online CVs by academics.

\section{Background}

\section{CVs in scientometric research}

Academic CVs can complement bibliometric databases and surveys because they may include multiple publication types (e.g., books, technical reports, preprints) and information about grants, awards, jobs, teaching and qualifications that may help science policy and research evaluation studies (Cañibano \& Bozeman, 2009). Dietz, Chompalov, Bozeman, Lane and Park (2000) conducted an early scientometric study on academic careers and the productivity of scientists and engineers based on coding CVs from U.S. Department of Energy (DOE) and National Science Foundation (NSF) funded projects, finding a relationship between age, subject areas, and early publication productivity and overall publication output. CVs have since been used for investigations of researcher mobility (e.g., Woolley \& Turpin 2009; Cañibano, Otamendi \& Solís, 2011), career impact (e.g., Gaughan, 2009; Cox et al., 2011), maps of scientific fields (Lepori \& Probst, 2009), gender differences (Leahey, 2006) and grant peer-review (e.g., Cañibano, Otamendi, \& Andújar, 2009). Other studies have used CVs with traditional bibliometric data for research evaluations (e.g., Lee \& Bozeman, 2005; Sabatier, Carrere \& Mangematin, 2006; Sandström, 2009).

Although several projects have collected and standardised CVs, such as Europass (http://europass.cedefop.europa.eu, see also EURO-CV, 2008), academics may not have an online CV, may infrequently update it or may only embed partial information about their academic activities. This issue may diminish, however since there has been a call for mandating online academic CVs with links to full-text publications (preprints/postprints) at the institutional level to be used by promotion committees and research funders (Hitchcock et al., 2003) and the same online standardised CVs have been proposed as a rich and cheap data source for the UK Research Assessment Exercise (RAE) (Harnad, Carr, Brody \& Oppenheim, 2003; Swan et al., 2005). A significant drawback for the practical use of online CVs in scientometrics, however, is that manually locating them may be difficult and time-consuming and automatic capturing online 
CVs by crawlers may not be possible without extensive manual data cleaning. Nevertheless, one advantage of online CVs is that they can potentially be used for webometric studies and in particular for link analyses of their contents.

\section{$O A$ and self-archiving}

Many organisations have launched their own OA repositories (see http://maps.repository66.org) and the European Commission has initiated OpenAIRE (http://www.openaire.eu) to promote OA repositories in Europe. In partial support, a small Danish survey found that respondents used OA journal archives or subject repositories at least monthly (Houghton, Swan \& Brown, 2011). To give evidence for the value of OA repositories, many studies have assessed the citation advantage of OA publications against non-OA counterparts (e.g., Harter, 1996; Lawrence, 2001; Antelman, 2004; Harnad \& Brody, 2004; Kurtz, 2004; Norris, Oppenheim, \& Rowland, 2008). The findings suggest that OA publications tend to attract more citations than non-OA publications, although a debate still exists. The citation benefit of OA research was greater for highly cited papers and found to be independent of other correlates of citation impact such as article age, journal impact factor, and number of co-authors. A recent study with a large sample of OA articles from 2002-2006 that were self-archived voluntarily or mandatorily (e.g., required by the employing institution) revealed that there was no citation advantage difference between non-mandated and mandated OA articles (Gargouri et al., 2010).

Most authors appear to be willing to self-archive their published research if their institutions or funders ask them to (see below: Swan \& Brown 2005). Moreover, a study found that self-archiving was allowed by $90 \%$ of 10,000 journals tested (Harnad et al., 2008; see also Coleman, 2007) and of the 1,256 publishers in the SHERPA/RoMEO database, 62\% (771) allow postprint self-archiving of the refereed final draft of articles and $8 \%$ allow only pre-refereeing archiving (preprints) (SHERPA/RoMEO, 2013). Nevertheless, a survey of 684 faculty members from 17 American doctorate-granting universities about self-archiving in institutional repositories showed that only $40 \%$ knew about such a platform (Kim, 2010). Within the same research population there were several negative (e.g., age, copyright concerns, time and effort) and positive (e.g., academic reward, altruism, self-archiving culture, and technical skills) factors that could influence self-archiving (Kim, 2011).

More recent investigations indicate a small but continuing proportional growth in OA publications. An investigation of over 1,800 peer reviewed journals in 2008 indicated that about $8.5 \%$ of articles were freely available online at the publishers' sites (gold OA) and an additional $12 \%$ could be found online by search engines (green OA), making the overall OA percentage about 20\% (Björk et al., 2010). A more recent study estimated that the proportion of gold OA journals (including delayed and hybrid OA) had increased from about $13.7 \%$ in 2008 to about 17\% in 2011 (Laakso \& Björk, 2012). Gargouri et al. (2012b) estimated the percentage growth for both green and gold OA across 14 subject areas based on a sample of 1,300 journal articles per year and per subject articles published during 2005-2010. The overall OA percentage was about $24 \%$ (21.4\% green OA and 2.4\% Gold OA) and so universal mandatory self-archiving could "almost immediately triple the baseline Green OA self-archiving rate" (Gargouri et al., 2012b, p. 292).

Academics have also been asked about self-archiving. Just under half of 1,296 authors across different subject areas and countries reported self-archiving at least one publication during the last three years through personal CVs or homepages (27\%), departmental websites $(20 \%)$ or subject-specific repositories (12\%) (Swan \& Brown, 2005). A majority would self-archive their 
published research if employers or funders requested or mandated it ( $81 \%$ and $14 \%$ willingly and reluctantly, respectively) and only 5\% would not accept OA mandates even if their employers or funders asked them to (Swan \& Brown 2005). Similarly, almost half (42\%) of the 811 respondents to a survey of EU project coordinators in an OA pilot found it easy to self-archive peer-reviewed articles (European Commission, 2012c). Nevertheless, self-reporting methods, such as surveys, may tend to give optimistic information. Moreover, a recent large-scale survey of 3,139 scholars across Europe showed that only 6\% associated the OA model with selfarchiving (Creaser et al., 2010, p. 152).

\section{Web outlink analyses}

Most webometric link analyses have used inlinks (links pointing to the website or web page analysed) and assessed the similarity between link metrics and offline scholarly-related metrics, such as journal Impact Factors (Vaughan \& Hysen, 2002) or university rankings (Thelwall, \& Harries, 2004). There have also been many investigations into interlinking between universities or departments and motivations for creating links and web citations (Bar-Ilan, 2005; Wilkinson, Harries, Thelwall, \& Price, 2003). Outlinks (links from a website or web page investigated) have been rarely investigated, perhaps because of the early webometric focus on impact studies and hence inlinks (Ingwersen, 1998). Nevertheless, outlinks can also be useful to investigate how people attempt to share resources irrespective of any impact these attempts may have had.

Ajiferuke and Wolfram (2004) found a significant difference between the mean ranks of outlinks from web pages from five selected domains (.edu, .com, .gov, .net, .org). Vaughan and $\mathrm{Wu}$ (2004) found significant positive correlations between both inlinks and outlinks and business measures (e.g., gross revenue, profit, R\&D expenditure) for commercial websites. GarcíaSantiago and Moya Anegón (2009) argued that web co-outlink analysis can help to explore relationships and to map triple helix structures (university-industry-government). Holmberg (2009) similarly concluded that co-outlinking can reveal shared interests and cooperation between organisations.

Two previous investigations of self-archiving practices have used web CVs and outlinks. Covey (2009) manually coded 771 publication lists from Carnegie Mellon University and found that that $45 \%$ of the faculty with publication lists self-archived at least one journal article. About $41 \%$ and $59 \%$ of the OA articles were the authors' own self-archived manuscripts and publishers' PDF versions, respectively, and there were clear disciplinary differences. Perhaps surprisingly, the departments of philosophy $(61 \%)$ and psychology (62\%) had the highest percentages of links to OA articles (Covey, 2009). On a larger scale, Más-Bleda, Thelwall, Kousha and Aguillo (in press) studied outlinks created by European highly cited scientists from 892 online homepages or personal websites to a range of pre-selected web sources and file types. Almost half (46\%) had at least one outlink to the selected websites, which were OA repositories, scholarly databases, social sites and publishers' websites. This investigation used 22 OA repositories, 38 journal publishers' websites and 4 book databases but no document sharing sites, online reference managers or social media tools. It focused on highly cited and productive researchers, mostly in the hard sciences and biomedical fields. These people are particularly important for science, but findings about their CVs are unlikely to also apply to typical researchers.

\section{Research questions}

This study assesses the extent to which scholars have OA-linking web CVs, personal home pages or publication lists (collectively described as web CVs for convenience from now on). For 
practical reasons, the scope of the study is limited to four subjects, chosen to cover science, engineering, social science and the humanities: astronomy \& astrophysics, public environmental \& occupational health, environmental engineering, and philosophy (including history and philosophy of science). Similarly, the scope is limited to 15 European countries, Bulgaria, Czech Republic, Denmark, Estonia, Finland, France, Germany, Hungary, Israel, Italy, the Netherlands, Poland, Slovenia, Spain, and the United Kingdom. The following research questions drive the investigation.

1. What proportion of EU researchers has a web CV (including publication lists and homepages) and does this vary by gender and status?

2. What proportion of EU researchers has a web CV linking to OA publications?

3. What proportion of EU researchers has a web CV linking to: publishers' websites; blogs and social network sites; multimedia resources?

4. Are the answers to the above questions influenced by country and academic subject?

\section{Methods and procedures}

For the first research question a large sample of academics in the chosen countries and subjects was needed. There is no definitive register of CVs or URLs for European researchers although there are some partial lists and some countries have comprehensive current research information systems. Hence we conducted a large-scale email survey, requesting URLs of web CVs and publication lists. This list was then supplemented with additional Google searches to be used for the second research question. A differences in proportions test with a Bonferroni correction (to reduce the risk of false positives from multiple tests) was used to check for differences between the percentage of people having CVs or the percentage of CVs having a type of hyperlink between countries, genders, statuses and disciplines. Country differences were only tested for between Eastern and Western Europe, unless stated, to avoid using too severe Bonferroni corrections for large numbers of comparisons.

\section{Email survey}

For the survey, we extracted a list of email addresses from published research papers indexed in the Thomson Reuters Web of Science (WoS) during 2005-2011 in the four chosen subjects. The email addresses were limited to the national domains of the 15 chosen EU countries as a practical step (e.g., uk, de). Due to the low WoS coverage of philosophy we exacted extra emails from publications indexed by Scopus and also included emails ending with non-national domains, such as com (e.g., gmail.com, yahoo.com, hotmail.com), org, and net, and verified the national locations of the authors from Scopus.

A questionnaire was devised to ask academics whether they had an online $\mathrm{CV}$, personal webpage, publication list or other site for academic purposes and also requested department, gender and academic post information (http://cybermetrics.wlv.ac.uk/survey-acumen.html). In each discipline we took a random sample of authors proportional to the total number of email addresses extracted for each country. The survey response rate ranged from $11.4 \%$ in philosophy to $6.6 \%$ in environmental engineering.

The 2,154 survey respondents were $71.7 \%(1,545)$ male and $27.7 \%$ (596) female, with 13 $(0.6 \%)$ giving no gender. For status, $21.4 \%$ (460) were full professors, 31.8\% (686) were associate professors/readers/senior lecturers, $15.1 \%$ (325) were assistant professors/lecturers, $14.3 \%$ (308) were postdoctoral research fellows, 6.5\% (141) were students (e.g., PhD or masters) and $10.9 \%$ (234) held other positions. In astronomy and astrophysics, environmental engineering 
and philosophy $74 \%-80 \%$ of the respondents were male. However, about $45 \%$ of the public health respondents were female, probably reflecting greater female participation in this field.

\section{Web CV sample}

To increase the sample size for web CVs from the email survey for the outlink analysis component (research question 2) we collected extra URLs through nation-specific Google searches (e.g., CV OR resume OR "curriculum vitae" OR "publication list" Astrophysics site:hu), randomly selecting and manually checking web CVs and publication lists from the results (Table 1 - see also the extended version, Appendix A, Table 4). This sample is likely to be biased. For example, it excludes researchers without a web presence or with a web presence that is difficult to find with Google and disproportionately includes authors that respond to email surveys.

Table 1. Sources of Web CV URLs (including homepages and publication lists).

\begin{tabular}{|l|l|l|l|l|l|l|}
\hline Discipline & $\begin{array}{l}\text { Email } \\
\text { invites }\end{array}$ & $\begin{array}{l}\text { Total } \\
\text { responses }\end{array}$ & $\begin{array}{l}\text { Response } \\
\text { rate }\end{array}$ & $\begin{array}{l}\text { URLs from } \\
\text { the survey }\end{array}$ & $\begin{array}{l}\text { URLs from } \\
\text { Google* }\end{array}$ & $\begin{array}{l}\text { Total } \\
\text { URLs }\end{array}$ \\
\hline Astronomy & 6,635 & $528(24.5 \%)$ & $7.96 \%$ & 271 & 386 & 657 \\
\hline Pub. Health & 7,277 & $534(25.8 \%)$ & $7.34 \%$ & 213 & 407 & 620 \\
\hline Environ. Eng. & 8,686 & $573(26.6 \%)$ & $6.60 \%$ & 284 & 330 & 614 \\
\hline Philosophy & 4,591 & $519(24.1 \%)$ & $11.41 \%$ & 342 & 467 & 809 \\
\hline Total & $\mathbf{2 7 , 1 8 9}$ & $\mathbf{2 , 1 5 4 ( 1 0 0 \% )}$ & $\mathbf{7 . 9 2 \%}$ & $\mathbf{1 , 1 1 0}$ & $\mathbf{1 , 5 9 0}$ & $\mathbf{2 , 7 0 0}$ \\
\hline
\end{tabular}

*This extra sample of URLs from Google searches was used only for the outlink analysis

\section{Web CV outlink analysis}

The SocSciBot web crawler (socscibot.wlv.ac.uk) and Webometric Analyst (lexiurl.wlv.ac.uk) were used to automatically extract and analyse outlinks from the 2,700 academics' web CVs. We classified the targets of outlinks from web CVs into four broad categories and several subcategories. This primarily reflects OA publishing but also includes other common targets: publishers' websites, social network sites, and scholarly-related multimedia. For a list of the URLs and file types used for this see http://cybermetrics.wlv.ac.uk/paperdata/WebResearchDisseminationEUCVs.xlsx.

\section{OA publications}

A web CV was counted as having an outlink to an OA publication if it had at least one link in any of the four types below (multiple links were ignored, even if of different types). Document file types are included in this class since a previous study showed that about $70 \%$ of OA documents in four science and four social science disciplines citing research papers were in nonHTML document format (PDF and DOC) (Kousha, 2009) and any non-HTML document format seems to be a good indicator of likely full text access.

- Major OA repository: 26 sites, including ArXiv.org in astronomy and astrophysics and philpapers.org in philosophy.

- National and institutional OA repositories and digital libraries: 765 sites from the 15 European countries in the study from http://opendoar.org/. Of these, 137 (18\%) had 
mandates in the Registry of Open Access Repositories Mandatory Archiving Policies (ROARMAP, http://roarmap.eprints.org).

- Document sharing sites: 7 sites, including DropBox.com and SlideShare.net.

- Document file types: word processed documents commonly used for preprints/postprints and other scholarly activities (e.g., file extensions doc, docx, rtf, dotx), presentations (e.g., ppt, pptx, key) and spreadsheet and statistical files (e.g., xls, xlsx, por, sav), which might be resources used in papers.

\section{Publishers' websites (including DOI URLs)}

A web CV was counted as having an outlink to a publisher's website if it had at least one link in any of the categories below. These are probably not OA outlinks and so are classified separately to record another way of publicising research. Presumably in some cases the publisher prohibits OA archiving (e.g., by about 30\% of publishers, see SHERPA/RoMEO, 2013), but in other cases the researcher may choose not to self-archive, even if it is allowed by the publisher, or the article may be OA in a publisher's website. Similarly, some books might have full text or previews available, or visitors might buy them.

- Major academic publishers (mostly for journals): 45 sites, such as Science Direct, Springer, and Oxford Journals. URLs were used for locations where abstracts of articles appear in the publishers' websites such as "journals.cambridge.org" instead of ".cambridge.org" to avoid counting irrelevant outlinks, when possible.

- Major book publishers, online bookshops and book databases: 30 sites (e.g., Amazon.com, Google Books, and Cambridge). Specific URLs were used for book sections of publishers' websites, when possible.

- Digital Object Identifiers (DOIs): DOI-based hyperlinks in academic CVs typically redirect to major publishers' websites.

\section{$\underline{\text { Blogs and social network sites }}$}

Blog posts, online reference mangers and general or professional social network sites may also be used to publicise research ( $\mathrm{Li}$, Thelwall \& Giustini, 2012; Shema, Bar-Ilan \& Thelwall, 2012). Although most social network sites are not designed for research, a link to them in an academic CV might suggest that the academic considers them to be relevant to their research in some way, such as for networking.

- Major blogs: 50 in different languages based on the Alexa.com top global sites list and directories of blogs. This includes popular general blogging sites, such as Blogspot.com, and blog sites in science and philosophy such as ScienceBlogs.com and Philosophyetc.net.

- Online reference managers: 13 sites, including Mendeley.com, that allow academics to share bibliographic information.

- Professional social network sites: 5 sites, such as LinkedIn.com and Academia.edu, for academic or professional audiences.

- General social network sites: 20 sites, including Facebook.com and popular European social network sites, such as vk.com. 


\section{$\underline{\text { Multimedia }}$}

Online videos are used for research communication (Kousha, Thelwall \& Abdoli, 2012; Sugimoto, \& Thelwall, 2013), as are images (e.g., in visual arts and astronomy) and recorded speeches and lectures (e.g., audio files).

- Video sharing sites: 16 general sites, such as YouTube, and scholarly-related sites, such as TedTalks.com, PhilosophyTalk.org and ScienceStage.com.

- Image sharing sites: 14 general sites, such as Flickr.com, and scientific sites, such as NASA Images.

- Video, audio and image file formats: 20 multimedia file extensions for video (e.g., mp4), audio (e.g., mov) and images (e.g., jpeg).

\section{Results}

Web CVs: About $61 \%(1,309)$ of the survey respondents reported having an academic web CV (including homepages and publication lists). Most (53\%) with CVs were full professors or associate professors/readers/senior lecturers. Perhaps surprisingly, philosophers reported having a Web CV the most often (Figure 1). A differences in proportions test between all pairs of disciplines found that all proportions were significantly different $(\mathrm{p}<0.001$ in all cases, with a Bonferroni correction for $\mathrm{n}=6$ tests), except for astronomy \& astrophysics (58.7\%) and environmental engineering $(60.3 \%)$.

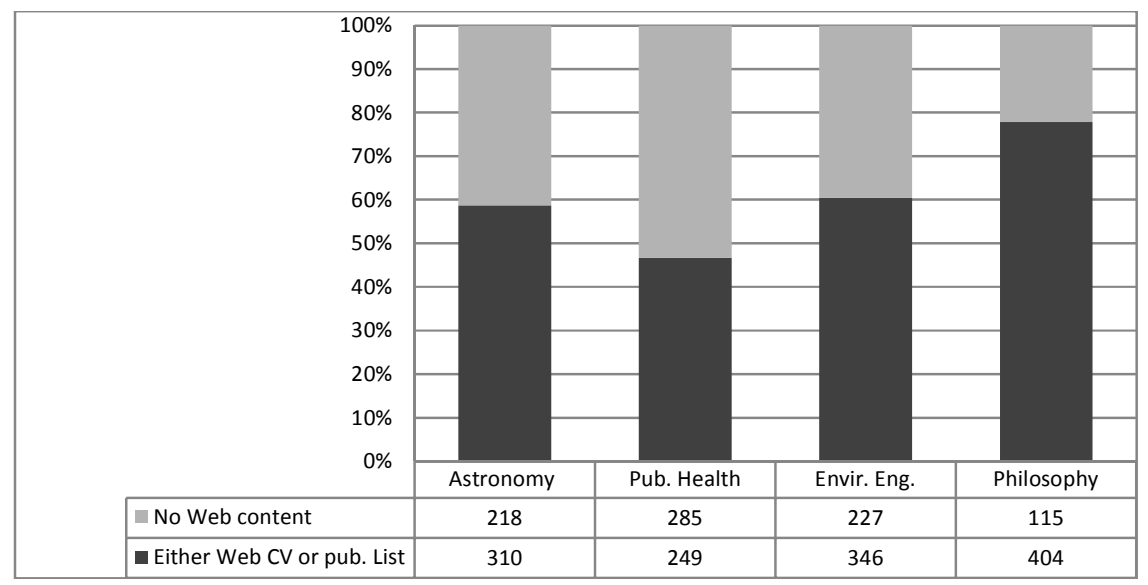

Figure 1. Email survey respondents $(n=2,154)$ with web $C V$ s by field.

A higher proportion of males $(65 \%)$ reported having a Web CV than did females (49\%) overall $(\mathrm{p}<0.001)$ and in each of the four disciplines (not always statistically significant). Full professors were more likely to have a web CV than any other group in the survey $(69 \%)$ but students $(41 \%)$ and postdocs $(51 \%)$ were the least likely (all differences significant $\mathrm{p}<0.001)$. There were similar differences in all subject areas except that the proportion of full professors with web CVs was similar to that of associate professors in both philosophy and environmental engineering. Web CV proportions were almost the same in Western Europe (60.6\%) and Eastern Europe (61.7\%), although individual countries varied (e.g., UK $71 \%$ vs. Spain $45 \%$ ).

Outlinks from Web CVs: A third (34\% or 920 of 2,700) of the web CVs had at least one outlink to an OA publication (Figure 2). Astronomy and astrophysics (48\%) and philosophy (37\%) had the most OA outlinks, whereas environmental engineering (29\%) and public health $(21 \%)$ had 
the least. All proportions were significantly different from each other $(p<0.001)$. The main differences are unsurprising because OA publishing has become the norm in astronomy and astrophysics and is common in philosophy, but not in public health and environmental engineering.

A much lower proportion of web CVs linked to the other three types of targets. In philosophy about $22 \%$ of the web CVs and in three other science disciplines about $16 \%$ had at least one outlink to a publisher's website. The philosophy percentage was significantly different from both public health and environmental engineering $(\mathrm{p}<0.05)$. In philosophy the proportion of academics with at least one outlink to a social media site (about 24\%) was nearly twice as much as in the three science fields and the difference was statistically significant $(\mathrm{p}<0.001$, but see the limitations below). This may reflect the importance of interactions and discussions in philosophy. Multimedia outlinks were significantly rarer in public health than in the other three fields $(\mathrm{p}<0.01)$ and most common in environmental engineering (difference only statistically significant with public health, $\mathrm{p}<0.05)$.

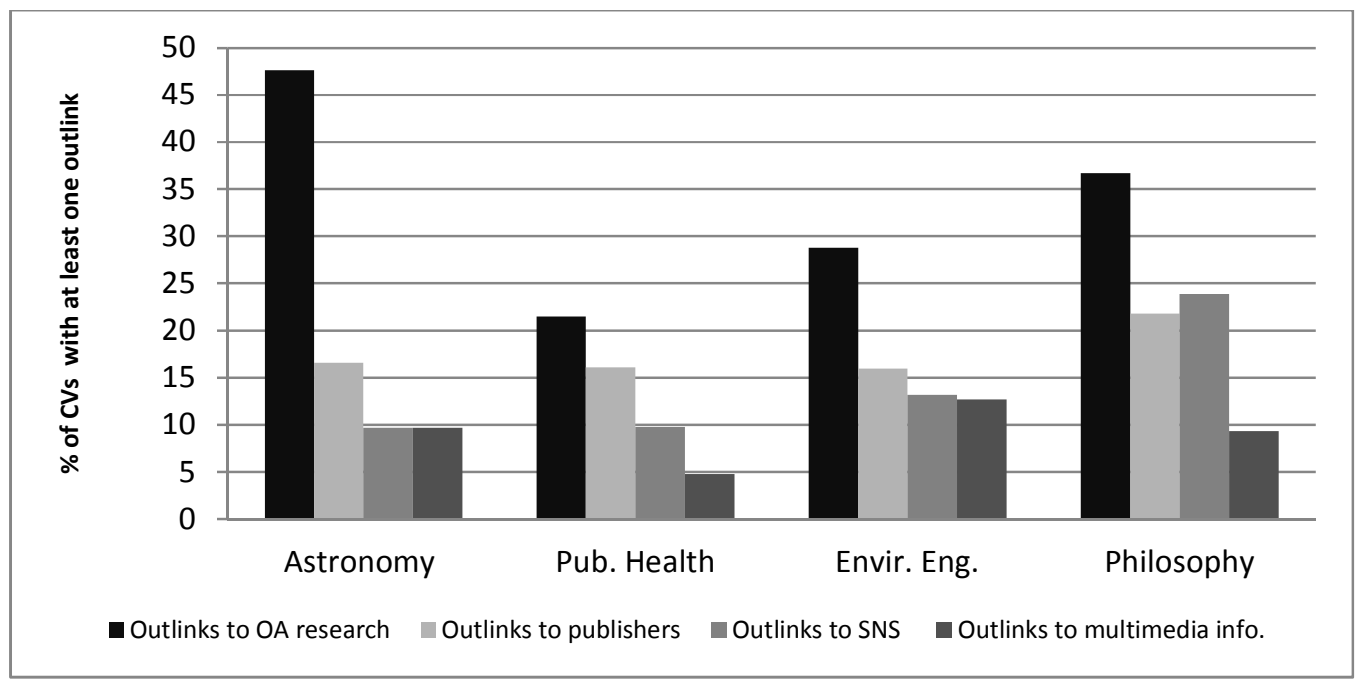

Figure 2. Common outlink targets of EU web CVs across subject areas.

More web CVs in Western EU countries had outlinks than those in Eastern countries in all categories (see also Appendix A, Table 5): OA research (39\% vs. 24\%), publishers (23\% vs. $9 \%)$, SNS (18\% vs. $9 \%)$ and multimedia files $(10 \%$ vs. $7 \%)$ ( $p<0.01$ or lower in all cases).

\section{Discussion}

Major OA archives: In terms of links from web CVs, OA archives are particularly important in astronomy and astrophysics (ArXiv, SAO/NASA Astrophysics Data System (ADS)) but almost irrelevant in environmental engineering (Table 2). Nevertheless, given that ArXiv and ADS seem to be almost universally used in astronomy and astrophysics (see also Nicholas et al., 2012), it is perhaps surprising that under half of the academic CVs in astrophysics had at least one OA outlink.

Broadly confirming this, a manual check of a random sample of 100 astronomy and astrophysics CVs found that 56\% had at least one OA link (e.g., ArXiv, ADS, PDF or Doc files), whereas 38\% had no hyperlinks and 6\% were not accessible. Of CVs without hyperlinks, $7 \%$ were in PDF format. Presumably many of the owners of HTML CVs without OA hyperlinks had 
articles in subject specific repositories (see Björk, Laakso, Welling \& Paetau, in press; Cullen \& Chawner, 2011), but did not link to them from their CVs because they couldn't or considered depositing in ArXiv or ADS to be sufficient.

In public health the majority of outlinks were to the US National Library of Medicine databases (NLM) and BiomedCentral.com (an online publisher of free peer-reviewed scientific articles). In philosophy and history and philosophy of science the dominant targets of outlinks were Philpapers.org, ArXiv, and PhilSci-Archive.

National and institutional archives: National and institutional archives had comparable uptake to the major archives in all disciplines except astronomy and astrophysics. In contrast to the three other disciplines, environmental engineering had a higher proportion of online CVs linking to national or institutional eprints archives (7\%) than to major OA repositories (1\%), however, presumably because no major archive serves this community. There was a relatively small difference between CVs with at least one outlink to mandated (18\%) and non-mandated (16\%) OA repositories (excluding the major OA archives) (see also Appendix A, Table 5).

Publishers' websites and academic databases: Table 2 reports the proportion of CVs with at least one outlink to a journal or book publisher website. In philosophy about $20 \%$ and $7 \%$ of the CVs had at least one outlink to the websites of journal publishers (including DOI links) and book publishers (including online bookshops), respectively, whereas in the three science fields this proportion was lower for journal publishers' websites (about 16\%) and much smaller for book publishers' websites (0.7\%-1.4\%). In philosophy Springer (9\%), Wiley (4\%) and Amazon.com (4\%), in astronomy and astrophysics the Institute of Physics (4\%), in public health Oxford University Press and Wiley (both 3\%) and in environmental engineering Elsevier (4\%) and Springer (3\%) were the most linked-to publishers. DOI outlinks occurred in about $4 \%$ of $\mathrm{CVs}$ in philosophy, astronomy and public health but about $8.5 \%$ in environmental engineering.

Blogs and other social network sites: Blogs seem to be particularly important in philosophy (Table 4). These blogs were created for variety of scholarly reasons, including scientific meeting announcements, course lectures and alternative homepages. In contrast, the automatically extracted links to social network sites did not seem to have been created for scholarly reasons. A manual checked of 60 outlinks to Facebook found that all outlinks were from hyperlinked icons to university or department Facebook pages, rather than academics' pages.

Online video and image sites: Environmental engineering and philosophy had the most multimedia outlinks, targeting YouTube videos in particular. Although some outlinks were to science videos, typically of lectures, manual checking revealed that most were from hyperlinked YouTube icons to institutional channels. Nearly all of the links to image sharing sites were from hyperlinked Flickr icons (e.g., university Flickr pages) rather than individually created scientific links.

Table 2. Web CVs with at least one outlink by target website types.

\begin{tabular}{|c|c|c|c|c|c|c|c|c|c|c|c|c|}
\hline \multirow[b]{2}{*}{ Disciplines } & \multicolumn{3}{|c|}{ Outlinks to OA websites } & \multicolumn{2}{|c|}{$\begin{array}{l}\text { Outlinks to } \\
\text { publishers or DOIs }\end{array}$} & \multicolumn{4}{|c|}{ Outlinks to social network sites } & \multicolumn{2}{|c|}{$\begin{array}{l}\text { Outlinks to videos } \\
\text { and images }\end{array}$} & \multirow[t]{2}{*}{$\begin{array}{l}\text { Any } \\
\text { outlink }\end{array}$} \\
\hline & $\begin{array}{l}\text { Major } \\
\text { OA } \\
\text { Repos. }\end{array}$ & $\begin{array}{l}\text { National } \\
\text { OA } \\
\text { Repos. }\end{array}$ & $\begin{array}{l}\text { Doc. } \\
\text { sharing }\end{array}$ & Jrnl./DOI & $\begin{array}{l}\text { Book } \\
\text { Publisher }\end{array}$ & $\begin{array}{l}\text { Major } \\
\text { blogs }\end{array}$ & $\begin{array}{l}\text { Online } \\
\text { ref. }\end{array}$ & $\begin{array}{l}\text { Prfs. } \\
\text { SNS }\end{array}$ & $\begin{array}{l}\text { Genl. } \\
\text { SNS }\end{array}$ & $\begin{array}{l}\text { Online } \\
\text { video }\end{array}$ & $\begin{array}{l}\text { Image } \\
\text { sharing }\end{array}$ & \\
\hline Astronomy & $\begin{array}{l}243 \\
(37 \%) \\
\end{array}$ & $\begin{array}{l}17 \\
(2.6 \%) \\
\end{array}$ & $\begin{array}{l}2 \\
(0.3 \%) \\
\end{array}$ & $\begin{array}{l}105 \\
(16 \%) \\
\end{array}$ & $\begin{array}{l}9 \\
(1.4 \%) \\
\end{array}$ & $\begin{array}{l}15 \\
(2.3 \%) \\
\end{array}$ & $\begin{array}{l}8 \\
(1.2 \%) \\
\end{array}$ & $\begin{array}{l}18 \\
(2.7 \%) \\
\end{array}$ & $\begin{array}{l}33 \\
(5 \%) \\
\end{array}$ & $\begin{array}{l}20 \\
(3 \%) \\
\end{array}$ & $\begin{array}{l}9 \\
(1.4 \%) \\
\end{array}$ & $\begin{array}{l}312 \\
(47.5 \%) \\
\end{array}$ \\
\hline $\begin{array}{l}\text { Pub. } \\
\text { Health }\end{array}$ & $\begin{array}{l}23 \\
(3.7 \%)\end{array}$ & $\begin{array}{l}18 \\
(2.9 \%)\end{array}$ & $\begin{array}{l}0 \\
(0 \%) \\
\end{array}$ & $\begin{array}{l}100 \\
(16.1 \%)\end{array}$ & $\begin{array}{l}6 \\
(1 \%) \\
\end{array}$ & $\begin{array}{l}4 \\
(0.6 \%)\end{array}$ & $\begin{array}{l}4 \\
(0.6 \%)\end{array}$ & $\begin{array}{l}17 \\
(2.7 \%)\end{array}$ & $\begin{array}{l}50 \\
(8.1 \%)\end{array}$ & $\begin{array}{l}21 \\
(3.4 \%)\end{array}$ & $\begin{array}{l}1 \\
(0.2 \%)\end{array}$ & $\begin{array}{l}154 \\
(24.8 \%)\end{array}$ \\
\hline
\end{tabular}




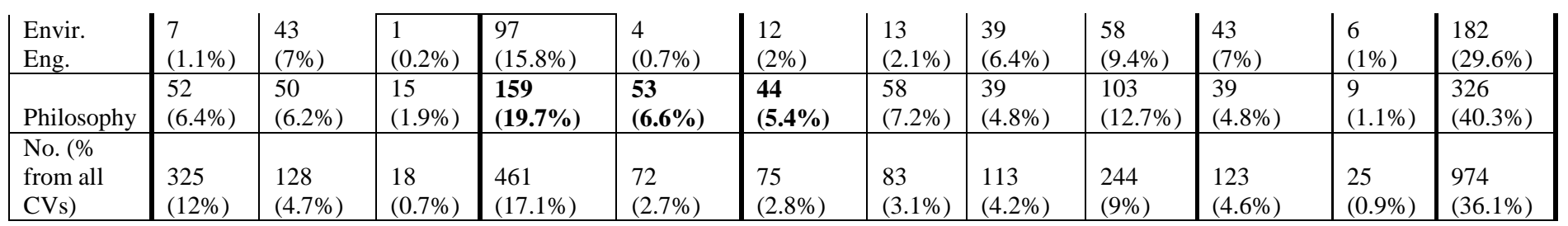

Outlinks by file type: Just over a quarter of the CVs had at least one outlink to a document file type (Table 3), although more in philosophy (34\%) and less in public health (19\%). Hence, it seems that at least in comparison to the limited set of fields examined, philosophy researchers are more willing to share preprints/postprints online, assuming that this is the nature of the linked-to files. Just under three-quarters (73\%) of the links to document file types were to PDF files, $8 \%$ to Microsoft Word files, $2.5 \%$ to presentation files (e.g., PowerPoint slides) and about $0.5 \%$ to Microsoft Excel files.

Although about $14 \%$ of the outlinks targeted image files, manual checking of 70 found that only $16 \%$ were created for scholarly reasons, such as images of galaxies and nebulas or scanned images of conference papers or posters. In philosophy we found a few (15) interesting outlinks to mp3 audio files. All were digitised lectures, speeches and podcasts of philosophers discussing philosophical topics (e.g., http://eis.bris.ac.uk/ plajb/research/index.html).

Table 3. Outlinks from web CVs and publication lists by file type.

\begin{tabular}{|c|c|c|c|c|c|c|c|c|}
\hline Disciplines & $\begin{array}{l}\text { Document } \\
\text { files }\end{array}$ & $\begin{array}{l}\text { Presentation } \\
\text { files }\end{array}$ & $\begin{array}{l}\text { Stat. } \\
\text { files }\end{array}$ & $\begin{array}{l}\text { Video } \\
\text { files }\end{array}$ & $\begin{array}{l}\text { Image } \\
\text { files }\end{array}$ & $\begin{array}{l}\text { Audio } \\
\text { files }\end{array}$ & $\begin{array}{l}\text { Archive } \\
\text { files }\end{array}$ & $\begin{array}{l}\text { Any file } \\
\text { type }\end{array}$ \\
\hline Astronomy & $\begin{array}{l}169 \\
(25.7 \%)\end{array}$ & $\begin{array}{l}6 \\
(0.9 \%)\end{array}$ & $\begin{array}{l}1 \\
(0.2 \%)\end{array}$ & $\begin{array}{l}4 \\
(0.6 \%)\end{array}$ & $\begin{array}{l}39 \\
(5.9 \%)\end{array}$ & $\begin{array}{l}5 \\
(0.8 \%)\end{array}$ & $\begin{array}{l}0 \\
(0.0 \%)\end{array}$ & $\begin{array}{l}186 \\
(28.3 \%)\end{array}$ \\
\hline $\begin{array}{l}\text { Pub. } \\
\text { Health }\end{array}$ & $\begin{array}{l}119 \\
(19.2 \%)\end{array}$ & $\begin{array}{l}2 \\
(0.3 \%)\end{array}$ & $\begin{array}{l}0 \\
(0.0 \%)\end{array}$ & $\begin{array}{l}1 \\
(0.2 \%)\end{array}$ & $\begin{array}{l}7 \\
(1.1 \%)\end{array}$ & $\begin{array}{l}1 \\
(0.2 \%)\end{array}$ & $\begin{array}{l}1 \\
(0.2 \%)\end{array}$ & $\begin{array}{l}123 \\
(19.8 \%)\end{array}$ \\
\hline $\begin{array}{l}\text { Envir. } \\
\text { Eng. }\end{array}$ & $\begin{array}{l}149 \\
(24.3 \%)\end{array}$ & $\begin{array}{l}7 \\
(1.1 \%)\end{array}$ & $\begin{array}{l}3 \\
(0.5 \%)\end{array}$ & $\begin{array}{l}3 \\
(0.5 \%)\end{array}$ & $\begin{array}{l}39 \\
(6.4 \%)\end{array}$ & $\begin{array}{l}0 \\
(0.0 \%)\end{array}$ & $\begin{array}{l}6 \\
(1.0 \%)\end{array}$ & $\begin{array}{l}172 \\
(28.0 \%)\end{array}$ \\
\hline Philosophy & $\begin{array}{l}274 \\
(33.9 \%)\end{array}$ & $\begin{array}{l}8 \\
(1.0 \%)\end{array}$ & $\begin{array}{l}0 \\
(0.0 \%)\end{array}$ & $\begin{array}{l}2 \\
(0.2 \%)\end{array}$ & $\begin{array}{l}34 \\
(4.2 \%)\end{array}$ & $\begin{array}{l}15 \\
(1.9 \%)\end{array}$ & $\begin{array}{l}1 \\
(0.1 \%)\end{array}$ & $\begin{array}{l}286 \\
(35.4 \%)\end{array}$ \\
\hline $\begin{array}{l}\text { No. (\%) } \\
\text { of all CVs }\end{array}$ & $\begin{array}{l}711 \\
(26.3 \%)\end{array}$ & $\begin{array}{l}23 \\
(0.9 \%)\end{array}$ & $\begin{array}{l}4 \\
(0.1 \%)\end{array}$ & $\begin{array}{l}10 \\
(0.4 \%)\end{array}$ & $\begin{array}{l}119 \\
(4.4 \%)\end{array}$ & $\begin{array}{l}21 \\
(0.8 \%)\end{array}$ & $\begin{array}{l}8 \\
(0.3 \%)\end{array}$ & $\begin{array}{l}767 \\
(28.4 \%)\end{array}$ \\
\hline
\end{tabular}

\section{Limitations}

The research findings are subject to a number of limitations. First, the survey had a low response rate and so the web CV analysis is based upon self-reported findings, probably biasing the results towards people with an online presence and hence the results are likely to be overestimates. In particular, academics may have not taken the time to find their web CV URLs.

The outlink analysis results were based upon heuristics, including assumptions that links from CVs or publication lists to document file types were always to freely-accessible full-text copies of an author's own research publications rather than to others' papers or teaching material. Similarly, links to known full-text OA archives were assumed to be to full-text copies of the CV owner's publications. In contrast, links to publishers' websites were assumed to be to bibliographic information about an article rather than a full text copy, but there will be gold OA and other exceptions such as sample articles in some fee-based journals. In terms of social media 
tools, most links were shown to be irrelevant by manual checking and so these statistics should be disregarded.

\section{Conclusions}

Since the advent of the web, many initiatives have sought to make research freely available online and to establish a proper infrastructure for researchers to publicise their scientific findings. Nevertheless, whilst a small majority of researchers seem to have web CVs, most do not use them to direct visitors to full-text research, and most seem not to direct visitors to any other major type of scholarly resource. Perhaps unsurprisingly, the proportion of scientists with web $\mathrm{CVs}$ and the proportion that link to various types of scholarly sites or resources varies by country, gender and discipline, even within the EU.

In terms of OA research, since a small majority of academics responding to the EU survey had a web presence and about a third of the CVs checked seemed to have at least one link to an OA publication, it seems that, very approximately, a fifth of EU academics have a OAlinking web presence. This is perhaps surprisingly low since most academics seem to be willing to self-archive their research if required (Swan \& Brown, 2005) and about $90 \%$ of journals and $62 \%$ of publishers let authors deposit preprints or postprints online (Harnad et al., 2008; SHERPA/RoMEO, 2013). Although some of the authors may have self-archived in OA repositories, especially in astronomy and astrophysics, this seems to be a clear missed opportunity to disseminate findings as fully as possible. This is alarming from the perspective of improving access to scientific information in the EU, particularly outside of astronomy and astrophysics.

The structure of CVs can also influence the extent of linking from CVs and perhaps also self-archiving at national or institutional levels, and this seems to be an easily fixable issue. For instance, about 60\% (18) of the CVs collected from the survey from Estonian authors were hosted in the Estonian Research Portal (https://www.etis.ee) of the Estonian Ministry of Education and Research. Its CV template seems to be not flexible enough to allow self-archiving by linking to full-text publications online. Nevertheless, developing standardised CV templates with hyperlinking capabilities does not guarantee OA self-archiving in a cause-and-effect manner and vice versa. It is not clear if pre-defined CV templates in individual academic institutions across the EU are seriously curtailing the OA publishing and self-archiving of research, but it is important that all institutional and national bodies providing templates or hosting for academic CVs should ensure that they promote or at least enable linking to full-text copies of publications. This could occur in parallel with efforts to establish effective mechanisms for research institutions and funders to create or strengthen mandates for self-archiving (see Gargouri et al., 2012a).

The gender, disciplinary and geographic differences found can help to target groups most needing help to create effective web CVs. Within the EU, Eastern countries, disciplines without established repositories and women seem to be particularly important in this respect. The disciplinary variations may be due to a lack of awareness within some research communities about self-archiving or other factors such as the structure of CVs, copyright issues with journals, or different disciplinary communication needs. International variations may be due to differing levels of infrastructure support, that policy makers should consider remedying if they wish to ensure that their national research is effectively disseminated, maximising the value for money of research support. 
Future research could analyse the variables assessed here in more detail. The proportion of web CVs linking to OA articles in different disciplines could be influenced by differences in the proportions of OA articles between subject areas (e.g., Gargouri et al., 2012b; Björk, Laakso, Welling \& Paetau, in press). For instance, mathematics (45\%) and earth sciences (33\%) have higher proportions than arts (10\%) and chemistry (13\%) (see Björk et al., 2010, p.8; Gargouri et al., 2012b, p. 288). Future research might assess the relationship between these two variables. The proportion of OA articles could perhaps be estimated either through the share of OA publications in the Directory of Open Access Journals for gold OA or by using web crawlers, search engines or academic databases for OA copies of both gold or green articles (e.g., Hajjem, Harnad, Gingras, 2005; Matsubayashi et al., 2008; Björk et al., 2010). Future studies can also analyse the difference between web CV links to green OA or gold OA across fields, and perhaps also investigate the impact of institutional and other mandates on the results.

\section{Acknowledgements}

Thank you to the reviewers for very helpful comments. This paper is supported by ACUMEN (Academic Careers Understood through Measurement and Norms) project, grant agreement number 266632, under the Seventh Framework Program of the European Union. This is an extended version of a paper accepted for presentation at the ISSI 2013 conference, Vienna, Austria.

\section{References}

Ajiferuke, I., \& Wolfram, D. (2004). Modelling the characteristics of web page outlinks. Scientometrics, 59(1), 43-62.

Antelman, K. (2004). Do Open-Access articles have a greater research impact? College \& Research Libraries, 65(5), 372-382. Retrieved January 13, 2013 from http://eprints.rclis.org/5463/1/do_open_access_CRL.pdf

Bar-Ilan, J. (2005). What do we know about links and linking? A framework for studying links in academic environments, Information Processing \& Management, 41(3), 973-986.

Björk, B-C., Laakso, M., Welling, P. \& Paetau, P. (in press). Anatomy of green open access, Journal of the American Society for Information Science and Technology. Retrieved May 30, 2013 from: http://www.openaccesspublishing.org/apc8/Personal\%20VersionGreenOa.pdf

Björk B-C., Welling, P., Laakso, M., Majlender, P., Hedlund, T., et al. (2010). Open access to the scientific journal literature: Situation 2009. PLoS ONE, 5(6), e11273.

Cañibano, C., \& Bozeman, B. (2009). Curriculum vitae method in science policy and research evaluation: The state-of-the-art. Research Evaluation, 18(2), 86-94.

Cañibano, C., Otamendi, F.J. \& Andújar, I. (2009). An assessment of selection processes among candidates for public research grants: The case of the Ramón y Cajal Programme in Spain. Research Evaluation, 18 (2), 153-161.

Cañibano, C., Otamendi, F.J. \& Solís, F. (2011). International temporary mobility of researchers: A crossdiscipline study. Scientometrics, 89(2), 653-675.

Coleman, A. (2007). Self-archiving and the copyright transfer agreements of ISI-ranked library and information science journals. Journal of the American Society for Information Science and Technology, 58(2), 286-296.

Covey, D. T. (2009). Self-archiving journal articles: A case study of faculty practice and missed opportunity. Portal, 9(2), 223-251.

Cox, M.F., Zhu, J., Ahn, B., London, J.S., Frazier, S., Torres-Ayala, A.T. \& Guerra, R.C.C. (2011). Choices for Ph.D.s in engineering: Analyses of career paths in academia and industry. ASEE Annual Conference and Exposition, Conference Proceedings, 11-12. 
Creaser, C., Fry, J., Greenwood, H., Oppenheim, C., Probets, S., Spezi, V., \& White, S. (2010). Authors' awareness and attitudes toward open access repositories. New Review of Academic Librarianship, 16 (SUPPL. 1), 145-161.

Cullen, R., \& Chawner, B. (2011). Institutional repositories, open access, and scholarly communication: A study of conflicting paradigms. Journal of Academic Librarianship, 37(6), 460-470.

Dietz, J., Chompolov, I., Bozeman, B., Lane, E. \& Park, J. (2000). Using the curriculum vita to study the career paths of scientists and engineers. Scientometrics, 49(3), 419-442.

EURO-CV: Building new indicators for researchers' careers and mobility based on electronic curriculum (2008). Retrieved January 3, 2013 from: http://www.uam.es/docencia/degin/prime/webprime/documentos/EuroCV/EURO\%20CV\%20report.pd f

European Commission (2012a). A Reinforced European Research Area Partnership for Excellence and Growth. Retrieved January 5, 2013 from: http://ec.europa.eu/euraxess/pdf/research_policies/eracommunication_en.pdf

European Commission (2012b). Online survey on scientific information in the digital age. Luxembourg: Publications Office. Retrieved January 5, 2013 from: http://ec.europa.eu/research/sciencesociety/document_library/pdf_06/survey-on-scientific-information-digital-age_en.pdf

European Commission (2012c). Survey on open access in FP7. Luxembourg: Publications Office of the European Union. Retrieved January 6, 2013 from: http://ec.europa.eu/research/sciencesociety/document_library/pdf_06/survey-on-open-access-in-fp7_en.pdf

García-Santiago, L., \& de Moya-Anegón, F. (2009). Using co-outlinks to mine heterogeneous networks. Scientometrics, 79(3), 681-702.

Gargouri, Y., Hajjem, C., Lariviére, V., Gingras, Y., Carr, L., Brody, T., \& Harnad, S. (2010). Selfselected or mandated, open access increases citation impact for higher quality research. PLoS ONE, 5(10), e13636, Retrieved May 30, 2013 from: http://www.plosone.org/article/info\%3Adoi\%2F10.1371\%2Fjournal.pone.0013636

Gargouri, Y., Larivière, V., Gingras, Y., Brody, T., Carr, L., \& Harnad, S. (2012a). Testing the Finch hypothesis on green OA mandate effectiveness. In, Open Access Week 2012, Retrieved May 30, 2013 from: http://eprints.soton.ac.uk/344687/

Gargouri, Y., Larivière, V., Gingras, Y., Carr, L., \& Harnad, S. (2012b). Green and gold open access percentages and growth, by discipline. In, 17th International Conference on Science and Technology Indicators (STI), Montreal, CA, 05 - 08, Sep 2012. 285-292. Retrieved May 31, 2013 from: http://sticonference.org/Proceedings/vol1/Gargouri_Green_285.pdf

Gaughan, M. (2009). Using the curriculum vitae for policy research: An evaluation of National Institutes of Health center and training support on career trajectories. Research Evaluation, 18(2), 117-124.

Hajjem, C., Harnad, S., \& Gingras, Y. (2005). Ten-year cross-disciplinary comparison of the growth of open access and how it increases research citation impact. IEEE Data Engineering Bulletin, 28(4), 3947, Retrieved May 30, 2013 from: http://eprints.soton.ac.uk/261688/1/ArticleIEEE.pdf

Harnad, S. (2006). Publish or perish - self-archive to flourish: the green route to open access, ERCIM News, 64, 12-13. Retrieved January 13, 2013 from http://eprints.soton.ac.uk/261715/1/harnadercim.pdf

Harnad, S. \& Brody, T. (2004). Comparing the impact of Open Access (OA) vs. non-OA articles in the same journals. D-Lib Magazine, 10(6). Retrieved March 14, 2010 from: www.dlib.org/dlib/june04/harnad/06harnad.html

Harnad, S., Brody, T., Vallieres, F., Carr, L., Hitchcock, S., Gingras, Y., Oppenheim, C., Hajjem, C. \& Hilf, E. (2008). The access/impact problem and the green and gold roads to open access: an update. Serials Review, 34(1), 36-40.

Harnad, S., Carr, L., Brody, T. \& Oppenheim, C. (2003). Mandated online RAE CVs linked to university eprint archives. Ariadne 35. Retrieved December 18, 2012 from: http://www.ariadne.ac.uk/issue35/harnad 
Harter, S. P. (1996). The impact of electronic journals on scholarly communication: A citation analysis. Public Access Computer Systems Review, 7(5), 5-34.

Hitchcock, S., Brody, T., Gutteridge, C., Carr, L. \& Harnad, S. (2003). The impact of OAI-based search on access to research journal papers, Serials, 16(3), 255-260.

Holmberg, K. (2009). Webometric network analysis: Mapping cooperation and geopolitical connections between local government administration on the web. Ph.D. dissertation, Åbo Akademi University, Department of information Science, Finland, Retrieved March 10, 2013 from: http://doria17kk.lib.helsinki.fi/bitstream/handle/10024/52528/HolmbergKim.pdf?sequence $=2$

Houghton, J. W., Swan, A. \& Brown, S. (2011). Access to research and technical information in Denmark. Report to The Danish Ministry of Science, Technology and Innovation (FI) and Denmark's Electronic Research Library (DEFF). Retrieved January 6, 2013 from: http://www.deff.dk/uploads/media/Access_to_Research_and_Technical_Information_in_Denmark.pdf

Ingwersen, P. (1998). The calculation of Web Impact Factors. Journal of Documentation, 54(2), 236-243.

Kim, J. (2010). Faculty self-archiving: Motivations and barriers. Journal of the American Society for Information Science and Technology, 61(9), 1909-1922.

Kim, J. (2011). Motivations of faculty self-archiving in institutional repositories. Journal of Academic Librarianship, 37(3), 246-254.

Kousha, K. (2009). Characteristics of open access web citation networks: A multidisciplinary study, Aslib Proceedings, 61(4), 394-406.

Kousha, K., Thelwall \& Abdoli, M. (2012). The role of online videos in research communication: A content analysis of YouTube videos cited in academic publications. Journal of the American Society for Information Science and Technology, 63(9), 1710-1727.

Kurtz, M.J. (2004). Restrictive access policies cut readership of electronic research journal articles by a factor of two, Harvard-Smithsonian Centre for Astrophysics, Cambridge, MA. Retrieved January 6, 2013 from: http://opcit.eprints.org/feb19oa/kurtz.pdf

Laakso, M. \& Björk, B. C. (2012). Anatomy of open access publishing: A study of longitudinal development and internal structure. BMC Medicine, Retrieved June 10, 2013 from: http://www.biomedcentral.com/content/pdf/1741-7015-10-124.pdf

Lawrence, S. (2001). Free online availability substantially increases a paper's impact. Nature, 411(6837), 521.

Leahey, E. (2006). Gender differences in productivity: Research specialization as a missing link. Gender and Society, 20(6), 754-780.

Lee, S. \& Bozeman, B. (2005). The impact of research collaboration on scientific productivity. Social Studies of Science, 35(5), 673-702.

Lepori, B. \& Probst, C. (2009). Using curricula vitae for mapping scientific fields: A small-scale experience for Swiss communication sciences. Research Evaluation, 18(2), 125-134.

Li, X., Thelwall, M., \& Giustini, D. (2012). Validating online reference managers for scholarly impact measurement. Scientometrics, 91(2), 461-471.

Más-Bleda, A. Thelwall, M., Kousha, K. and Aguillo, I.F. (in press). Successful researchers publicizing research online: An outlink analysis of European highly cited scientists' personal websites. Journal of Documentation.

Más-Bleda, A., and Aguillo, I.F. (2013). Can a personal website be useful as an information source to assess individual scientists? The case of European highly cited researchers, Scientometrics, DOI: 10.1007/s11192-013-0952-5

Matsubayashi, M., Kurata, K., Sakai, Y., Morioka, T., Kato, S., Mine, S., \& Ueda, S. (2009). Status of open access in the biomedical field in 2005. Journal of the Medical Library Association, 97(1), 4-11, Retrieved May 30, 2013 from: http://www.ncbi.nlm.nih.gov/pmc/articles/PMC2605039/pdf/mlab-9701-4.pdf

Nicholas, D., Rowlands, I., Watkinson, A., Brown, D., \& Jamali, H. R. (2012). Digital repositories ten years on: What do scientific researchers think of them and how do they use them? Learned Publishing, 25(3), 195-206. 
Norris, M., Oppenheim, C., \& Rowland, F. (2008). The citation advantage of open-access articles. Journal of the American Society for Information Science and Technology, 59(12), 1963-1972.

Sabatier, M., Carrere, M. \& Mangematin, V. (2006). Profiles of academic activities and careers: Does gender matter? An analysis based on French life scientist CVs. Journal of Technology Transfer, 31(3), 311-324.

Sale, A. (2006). The acquisition of open access research articles. First Monday, 11(10), Retrieved Jun 3, 2013 from: http://eprints.utas.edu.au/388/1/FirstMondayOct06.pdf

Sandström, U. (2009). Combining curriculum vitae and bibliographic analysis: Mobility, gender, and research performance. Research Evaluation, 18(2), 135-142.

Shema H., Bar-Ilan J. \& Thelwall M. (2012). Research blogs and the discussion of scholarly information. PLoS ONE, 7(5), e35869, Retrieved May 11, 2013 from: http://www.plosone.org/article/info\%3Adoi\%2F10.1371\%2Fjournal.pone.0035869

SHERPA/RoMEO (2013). Statistics for the 1256 publishers in the RoMEO database, Retrieved Jun 4, 2013 from: http://www.sherpa.ac.uk/romeo/statistics.php?colour=green

Sugimoto, C.R. \& Thelwall, M. (2013). Scholars on soap boxes: Science communication and dissemination in TED videos, Journal of the American Society for Information Science and Technology, 64(4), 663-674.

Swan, A. \& Brown, S. (2005). Open access self-archiving: an author study, JISC Technical Report, pp. 1-97. Retrieved December 18, 2012 from: http://eprints.ecs.soton.ac.uk/10999/01/jisc2.pdf

Swan A., Needham P., Probets S., Muir A., Oppenheim C., O'Brien A., Hardy R., Rowland F. \& Brown S. (2005). Developing a model for e-prints and open access journal content in UK further and higher education. Learned Publishing, 18(1), 25-40.

Thelwall, M., \& Harries, G. (2004). Do the Web sites of higher rated scholars have significantly more online impact? Journal of the American Society for Information Science and Technology, 55(2), 149159.

Vaughan, L. \& Hysen, K. (2002). Relationship between links to journal Web sites and Impact Factors. Aslib Proceedings, 54(6), 356-361.

Vaughan, L., \& Wu, G. (2004). Links to commercial websites as a source of business information. Scientometrics, 60(3), 487-496.

Wilkinson, D., Harries, G., Thelwall, M. \& Price, E. (2003). Motivations for academic web site interlinking: Evidence for the web as a novel source of information on informal scholarly communication, Journal of Information Science, 29(1), 59-66.

Woolley, R. \& Turpin, T. (2009). CV analysis as a complementary methodological approach: Investigating the mobility of Australian scientists. Research Evaluation, 18(2), 143-151.

Xia, J., Myers, R.L., \& Wilhoite, S.K. (2011). Multiple open access availability and citation impact. Journal of Information Science, 37(1), 19-28. 


\section{Appendix A}

\begin{tabular}{|c|c|c|c|c|c|c|c|c|c|c|c|c|c|c|c|}
\hline \multicolumn{4}{|c|}{ Astronomy \& Astrophysics } & \multicolumn{3}{|c|}{$\begin{array}{l}\text { Public environmental \& occupational } \\
\text { health }\end{array}$} & \multicolumn{3}{|c|}{ Environmental engineering } & \multicolumn{3}{|c|}{$\begin{array}{l}\text { Philosophy; History and philosophy } \\
\text { of science }\end{array}$} & \multicolumn{3}{|c|}{ Total } \\
\hline EU countries & Answered & $\begin{array}{l}\text { CVs URLS } \\
\text { from the } \\
\text { survey } \\
\text { (Survey } \\
\text { +Google) }\end{array}$ & $\begin{array}{l}\% \\
\text { survey } \\
\text { response } \\
\text { rate }\end{array}$ & Answered & $\begin{array}{l}\text { CVs URLS } \\
\text { from the } \\
\text { survey } \\
\text { (Survey } \\
\text { +Google) }\end{array}$ & $\begin{array}{l}\% \\
\text { survey } \\
\text { response } \\
\text { rate }\end{array}$ & Answered & $\begin{array}{l}\text { CVs URLS } \\
\text { from the } \\
\text { survey } \\
\text { (Survey } \\
\text { +Google) }\end{array}$ & $\begin{array}{l}\% \\
\text { survey } \\
\text { response } \\
\text { rate }\end{array}$ & Answered & $\begin{array}{l}\text { CVS URLS } \\
\text { from the } \\
\text { survey } \\
\text { (Survey } \\
\text { +Google) }\end{array}$ & $\begin{array}{l}\% \\
\text { survey } \\
\text { response } \\
\text { rate }\end{array}$ & Answered & $\begin{array}{l}\text { CVs URLs } \\
\text { from the } \\
\text { survey } \\
\text { (Survey } \\
\text { +Google) }\end{array}$ & $\begin{array}{l}\% \\
\text { survey } \\
\text { response } \\
\text { rate }\end{array}$ \\
\hline UK & 71 & $47(47)$ & 66.2 & 79 & $49(49)$ & 63.3 & 51 & $35(50)$ & 68.63 & 140 & $110(110)$ & 78.57 & 341 & $241(256)$ & 70.67 \\
\hline Spain & 71 & $32(53)$ & 45.07 & 68 & $16(48)$ & 23.5 & 80 & $36(44)$ & 45 & 67 & $46(73)$ & 68.66 & 286 & $130(218)$ & 45.45 \\
\hline Slovakia & 9 & $6(37)$ & 66.67 & 6 & $3(24)$ & 50 & 10 & $5(35)$ & 50 & 11 & $6(44)$ & 54.55 & 36 & $20(140)$ & 55.56 \\
\hline Poland & 24 & $18(59)$ & 75 & 20 & $7(41)$ & 35 & 41 & $15(40)$ & 36.59 & 10 & $8(54)$ & 80 & 95 & $48(194)$ & 50.53 \\
\hline Netherlands & 50 & $35(48)$ & 70 & 64 & $41(55)$ & 64.1 & 50 & $33(43)$ & 66 & 40 & $30(57)$ & 75 & 204 & $139(203)$ & 68.14 \\
\hline Italy & 75 & $37(49)$ & 49.33 & 56 & $29(51)$ & 50 & 85 & $58(58)$ & 68.24 & 72 & $62(89)$ & 86.11 & 288 & $188(247)$ & 65.28 \\
\hline Israel & 25 & $17(41)$ & 68 & 22 & $13(30)$ & 59.1 & 32 & $20(40)$ & 62.5 & 21 & $16(40)$ & 76.19 & 100 & $66(151)$ & 66.00 \\
\hline Hungary & 18 & $16(49)$ & 88.89 & 7 & $6(40)$ & 85.7 & 29 & $24(43)$ & 79.31 & 5 & $4(41)$ & 80 & 59 & $50(173)$ & 84.75 \\
\hline Germany & 63 & $37(52)$ & 58.73 & 51 & $25(48)$ & 51 & 30 & $17(46)$ & 56.67 & 59 & $47(55)$ & 79.66 & 203 & $126(201)$ & 62.07 \\
\hline France & 53 & $25(47)$ & 47.17 & 34 & $5(58)$ & 14.7 & 31 & $19(41)$ & 61.29 & 45 & $34(47)$ & 75.56 & 163 & $83(193)$ & 50.92 \\
\hline Finland & 22 & $9(24)$ & 40.91 & 38 & $8(33)$ & 21.1 & 32 & $13(42)$ & 40.63 & 11 & $9(44)$ & 81.82 & 103 & $39(143)$ & 37.86 \\
\hline Estonia & 4 & $4(25)$ & 100 & 5 & $3(22)$ & 60 & 18 & $12(22)$ & 66.67 & 3 & $3(25)$ & 100 & 30 & $22(94)$ & 73.33 \\
\hline Denmark & 17 & $13(41)$ & 76.47 & 68 & $36(53)$ & 51.5 & 48 & $39(43)$ & 81.25 & 22 & 19(57) & 86.36 & 155 & 107(194) & 69.03 \\
\hline Czech & 19 & $12(38)$ & 63.16 & 11 & $6(36)$ & 54.6 & 29 & $18(44)$ & 62.07 & 11 & $9(42)$ & 81.82 & 70 & $45(160)$ & 64.29 \\
\hline Bulgaria & 7 & $2(47)$ & 28.57 & 5 & $2(32)$ & 40 & 7 & $2(23)$ & 28.57 & 2 & $1(31)$ & 50 & 21 & $7(133)$ & 33.33 \\
\hline TOTAL & 528 & $310(657)$ & 58.71 & 534 & $249(620)$ & 46.6 & 573 & $346(614)$ & 60.38 & 519 & 404(809) & 77.84 & 2154 & $1,309(2,700)$ & 60.77 \\
\hline
\end{tabular}


Table 5. Web CVs with at least one outlink by field and country.

\begin{tabular}{|l|l|l|l|l|l|l|}
\hline Countries & Astronomy & $\begin{array}{l}\text { Pub. } \\
\text { Health }\end{array}$ & $\begin{array}{l}\text { Envir. } \\
\text { Eng. }\end{array}$ & $\begin{array}{l}\text { Philoso } \\
\text { phy }\end{array}$ & $\begin{array}{l}\text { OA } \\
\text { mandates } \\
* *\end{array}$ & $\begin{array}{l}\text { OA } \\
\text { archives } \\
* *\end{array}$ \\
\hline UK & $73.3 \%$ & $58.7 \%$ & $71.7 \%$ & $74.3 \%$ & 58 & 209 \\
\hline Italy & $51.0 \%$ & $39.2 \%$ & $62.3 \%$ & $46.1 \%$ & 30 & 72 \\
\hline Finland & $66.7 \%$ & $39.4 \%$ & $42.9 \%$ & $50.0 \%$ & 28 & 14 \\
\hline Spain & $54.7 \%$ & $27.1 \%$ & $41.9 \%$ & $56.4 \%$ & 14 & 98 \\
\hline Germany & $69.2 \%$ & $43.8 \%$ & $45.3 \%$ & $61.3 \%$ & 13 & 165 \\
\hline France & $63.8 \%$ & $32.8 \%$ & $48.7 \%$ & $61.7 \%$ & 12 & 71 \\
\hline Denmark & $65.9 \%$ & $45.3 \%$ & $65.1 \%$ & $56.1 \%$ & 4 & 11 \\
\hline Poland & $49.2 \%$ & $31.7 \%$ & $20.0 \%$ & $55.6 \%$ & 3 & 75 \\
\hline Netherlands & $47.9 \%$ & $65.5 \%$ & $46.7 \%$ & $59.6 \%$ & 3 & 24 \\
\hline Hungary & $28.6 \%$ & $20.0 \%$ & $35.8 \%$ & $56.1 \%$ & 3 & 13 \\
\hline Czech & $36.8 \%$ & $8.3 \%$ & $38.6 \%$ & $54.8 \%$ & 0 & 8 \\
\hline Bulgaria & $48.9 \%$ & $18.8 \%$ & $21.7 \%$ & $17.5 \%$ & 0 & 6 \\
\hline Estonia & $36.0 \%$ & $13.6 \%$ & $59.1 \%$ & $33.3 \%$ & 0 & 5 \\
\hline Israel & $73.2 \%$ & $36.7 \%$ & $57.8 \%$ & $42.5 \%$ & 0 & 2 \\
\hline Slovakia & $54.1 \%$ & $12.5 \%$ & $11.4 \%$ & $31.8 \%$ & 0 & 0 \\
\hline
\end{tabular}

*High and low percentages of outlinks are highlighted in bold and italic respectively. **EU countries are arranged based on number of OA mandates as recorded in Registry of Open Access Repositories Mandatory Archiving Policies (ROARMAP, http://roarmap.eprints.org), ***number of OA repositories as recorded in Directory of Open Access Repositories (http:// http://www.opendoar.org) 